\title{
La construcción del pasado chubutense en el discurso histórico provincial: representaciones de la experiencia exploratoria y colonizadora española en Chubut, Argentina, en textos escolares provinciales (1978-2006)
}

\author{
The construction of Chubut's past in the provincial historical discourse: \\ representations of the Spanish exploratory and colonizing experience in \\ Chubut, Argentina, in school textbooks (1978-2006)
}

\author{
José Guillermo Williams \\ jgwilliams_85@yahoo.com.ar \\ Pesquisador \\ Instituto de Estudios Sociales y Políticos de la Patagonia (IESyPPat) \\ Universidad Nacional de la Patagonia San Juan Bosco (UNPJSB) \\ Guerrico, 346 - Rada Tilly \\ 9001 - Chubut \\ Argentina
}

\begin{abstract}
Resumen
En este trabajo nos proponemos analizar de qué modo se ha representado la experiencia exploratoria y colonizadora española en el territorio de la actual provincia de Chubut, Argentina, en los textos escolares de educación primaria de producción provincial. Para ello iniciamos el artículo explicando el rol de la educación y los textos escolares en la conformación de la historia y la identidad de un territorio, y luego nos referimos brevemente al papel que ha jugado la "hispanidad" en la nación y en la provincia, especialmente desde principio del siglo XX, pero también en la actualidad. Tras una descripción de lo que denominamos la "experiencia española" en Chubut, analizamos cinco textos escolares, viendo cómo esta experiencia es representada en cada uno de ellos. El artículo finaliza explicando que el rol asignado va variando entre un texto y en otro, pero, a pesar de aparecer siempre, su papel nunca llega a ser más relevante que otros episodios históricos de la provincia, principalmente el de la colonización galesa.
\end{abstract}

\section{Palabras-clave}

Educación; Identidad; Historia.

\begin{abstract}
The following paper proposes to analyze the ways in which Chubut school textbooks have represented the Spanish exploratory and colonizing experience in the current territory of Chubut, Argentina. We start the article by explaining the role of education and school textbooks in the conformation of a territory's history and identity, and then we briefly refer to the role played by "Hispanity" in the nation and the province, especially since the early $20^{\text {th }}$ century, but also in current time. After describing what we call the "Spanish experience" in Chubut, we analyze five school textbooks, seeing how this experience is represented in each of them. The article ends by explaining that the assigned role varies between one text and the other but, despite its continuous appearance, its importance never manages to be bigger than other historical episodes of Chubut, chiefly, the Welsh settlement.
\end{abstract}

\section{Keywords}

Education; Identity; History.

Recibido el: 31/8/2015

Aceptado el: 10/11/2015 
La escuela representa uno de los principales espacios utilizados por el Estado para producir y reproducir el discurso oficial de pertenencia a un determinado territorio y a una determinada cultura, siendo el ejemplo principal la Nación. Esto se logra principalmente a través de la conformación del curriculum correspondiente a Historia. Como explica Luis Alberto Romero, "La Historia fue en la escuela no solo una disciplina de saber, sino un poderoso instrumento para identificar con la comunidad nacional a cada futuro ciudadano que pasaba por sus aulas" (ROMERO 2004, p. 39-40). En este ámbito, el libro de texto constituye la principal herramienta de reproducción del curriculum. Héctor Rubén Cucuzza afirma que "[...] la influencia del libro escolar no es menor en la conformación de las identidades nacionales a través de tradiciones inventadas o los mecanismos por los cuales determinadas comunidades se imaginan a sí mismas $[. . .]^{\prime \prime}$ (CUCUZZA 2007, p. 59).

Este proceso de construcción del pasado y la identidad se realiza de manera similar a nivel regional y provincial. Aquí, se construye una narración de la historia de la provincia, estableciendo así cuales fueron sus actores y acciones principales, y cómo la provincia fue definida por estos procesos históricos. Para articular estos contenidos curriculares, se han diseñado y producido una serie de libros de texto escolares, dedicados a cubrir aspectos geográficos, biológicos, históricos y culturales de la provincia.

En el caso de la provincia de Chubut, Argentina, que trabajaremos aquí, los libros de texto escolares han partido de una concepción de la historia pensada desde la Dirección de Cultura y Educación, que plantea dos pilares que estructuran la historia provincial: la experiencia exploradora española, durante el periodo colonial (1492-1810), y la presencia definitiva, inaugurada por la colonización establecida por galeses a partir de 1865. Si bien el segundo es, indiscutiblemente, el elemento más fuerte en la construcción del pasado provincial, la experiencia española adquiere un carácter de relevancia en estos textos, en cuanto ayuda a introducir al territorio del Chubut en los procesos de exploración por parte de europeos que ocurrían simultáneamente en el resto del continente americano, centrándose en el proceso colonizador español. Paralelamente, en cuanto la "Hispanidad" comenzó a ser pensada desde principios del siglo XX como un elemento fundante de la identidad nacional1, la exaltación de este elemento hispano como constitutivo del pasado chubutense representa un intento de enmarcar la identidad regional en la nacional.

El propósito de este trabajo es analizar las representaciones de la "experiencia española" en Chubut en los contenidos históricos de los libros de texto escolares provinciales. Nuestro interés reside en analizar el espacio que se le otorga a la temática dentro del reducido cuerpo del texto, distinguir qué elementos son resaltados y qué individuos son mencionados, así como también ver el rol asignado a estos episodios dentro de la historia provincial.

Nuestras fuentes consistirán en cinco documentos, producidos en el periodo 1978-2006. El primero consiste en una carpeta titulada "Chubut mi provincia",

${ }^{1}$ Especialmente vista como un rescate de una identidad "original" frente al aluvión migratorio. 
realizada por el Consejo Provincial de Educación de Chubut en 1978 con el objetivo de recopilar información para elaborar un libro de texto. Seguidamente, trabajaremos cuatro libros de texto escolares producidos para el estudio de la provincia en la educación primaria. Estos son: Chubut mi Provincia, de la década de 1980, Chupat Chubut de 1991, Sentir Chubut de 1998 y Chubut Pura Naturaleza, de 2006 (reeditado en 2010).

\section{Historiografía y educación: formas deconstruir nacionalidad y provincialidad}

La escritura de la historia de un territorio (geográfico o administrativo) representa un elemento central en la construcción de la identidad de su población. En esta escritura no sólo se dan cuenta los acontecimientos ocurridos en el mismo, sino que estos son estructurados, asignándosele un sentido específico, y conformado así un discurso. La historiografía se ha ocupado ampliamente de la escritura de las historias nacionales, fuertemente ligadas a los nacionalismos. En el ámbito de las historias territorianas y provinciales, la dinámica de construcción de estos pasados opera de manera similar a la de la nación. Estas historias pueden plantear continuidades, similitudes o diferencias con la historia nacional, pueden resaltar cómo su poblamiento y crecimiento se desarrolló en consonancia con los planes del Estado nacional, o bien distinguir características que destacan sus particularidades respecto al resto del país. Y precisamente, tienen por objetivo enmarcar la identidad de su población en clave histórica.

Para lograr constituir una identidad, esta historia oficial es también didactizante, y esto lo hace a través de ejemplos que resaltan los valores que el Estado (nacional, provincial) pretende promover. Fernando Devoto explica que la escuela, uno de los órganos principales para esta tarea,

[...] jugó un rol de significación a los efectos de imponer un conjunto de valores sobre los habitantes de un determinado territorio, el hecho de cuáles eran los valores que debían enfatizarse y cuales los instrumentos de transmisión de los mismos pudo presentar relevantes diferencias en los distintos casos nacionales (DEVOTO 1992, p. 9).

En este sentido, debemos pensar a los libros de texto escolares como uno de los ejes que articulan la educación primaria y secundaria. Ellos son utilizados tanto por los alumnos como por los maestros y profesores en las prácticas de aprendizaje y enseñanza que se establecen dentro del aula. Como explican Palmira Dobaño Fernández y Martha Rodríguez:

Los libros de texto son los materiales curriculares con mayor incidencia en el aprendizaje en el aula y que tienen un rol directivo y configurador de la práctica docente que los hace cualitativamente diferentes de los demás recursos. Aún fuera del aula, en general, la mayor parte del tiempo que los alumnos dedican a sus estudios y tareas gira en torno de los libros de texto (DOBAÑO FERNANDEZ; RODRIGUEZ 2009, p. 480).

El análisis de los libros escolares, y sus usos ha generado una importante producción académica, dedicada a trabajar múltiples facetas, desde la clasificación 
de la variada literatura escolar, hasta los discursos que reproducen y los usos y prácticas que establecen.

Alain Choppin explica que el libro escolar posee múltiples funciones: la referencial, la instrumental, la ideológica-cultural y la documental. Para este trabajo nos focalizaremos en la primera y la tercera función. Como explica Negrín, Choppin plantea que en la función referencial, también llamada curricular o programática,

[...] el manual traduce las prescripciones curriculares más amplias y constituye el soporte privilegiado de los contenidos educativos, es depositario de conocimientos, de técnicas o de competencias que un grupo social estima necesario transmitir a las nuevas generaciones (NEGRIN 2009, p. 192).

Choppin considera la función ideológica y cultural como la más antigua. Surge con los Estados nacionales y los sistemas educativos modernos, donde el libro de texto se establece "[...] como uno de los instrumentos esenciales que moldean la lengua, la cultura y los valores de las clases dirigentes" (NEGRIN 2009, p. 192). En esta misma línea, Egil Børre Johnsen explica que "tradicionalmente, los estudios se han basado en el deseo de describir la imagen que se hace la nación de sí misma, tal como se presenta en los libros de texto" (JOHNSEN 1996, p. 74). Pensando en estas funciones, coincidimos también con Johnsen, al citar a Ruth Miller Elson, quien "[...] considera los libros escolares como un reflejo de los objetivos políticos y culturales prevalecientes de una sociedad. El análisis de Elson sobre los puntos de vista y las actitudes se basa en la suposición de que los libros de texto son el espejo ultimo del poder" (JOHNSEN 1996, p. 115).

Esto también concuerda con las categorías de análisis de libros escolares propuestas por Johnsen, siendo la primera que propone la del análisis de "ideología en el libro de texto". Volviendo a Negrín, compartimos su afirmación de que "[...] el libro, en su esencia pedagógica, mantiene el sentido original para el que fue concebido: la distribución de un conocimiento "legitimo" en el ámbito de las escuelas" (NEGRIN 2009, p. 189). Entre las herramientas disponibles para llevar a cabo este tipo de análisis, tomamos dos de las que plantea Johnsen: el análisis cuantitativo del contenido y el método hermenéutico o descriptivo analítico.

El estudio de los diversos aspectos de la provincia del Chubut comprende un espacio curricular reducido y localizado en la educación general básica chubutense. Dado el carácter centralista que poseían (y poseen) los libros de texto producidos a nivel nacional, la cobertura de los espacios regionales y provinciales más allá de Buenos Aires debían ser cubiertos por producciones propias.

En el periodo temporal que cubrimos, desde mediados de la década de 1970 hasta la actualidad, este espacio se incluye en el cuarto grado de la escuela primaria, perteneciente al segundo ciclo de la Educación General Básica, el cual fue reformado en la década de 1990 y nuevamente en la década de 2000, pero siempre manteniéndose, más allá de los cambios de nomenclatura, en el cuarto año de la escuela primaria. 
El material básico con el que tanto alumnos como maestros trabajan la provincia es provisto por libros de texto o manuales, requeridos, encomendados, aprobados e incluso producidos por el Ministerio de Educación de la provincia, y comprenden los varios aspectos de la provincia: geográfico y climático, histórico, humano y natural. En este sentido vemos una "naturaleza calidoscópica de los libros de texto y de su investigación" (JOHNSEN 1995, p. 25).

\section{Hispanidad, argentinidad y la "identidad chubutense". Pensando en el siglo $\mathrm{XX}$}

En 1992, en el $500^{\circ}$ aniversario del arribo de Cristóbal Colón a América, un grupo de jóvenes oriundos de Comodoro Rivadavia realizó una travesía en el catamarán "Gandul", de construcción local, que consistió en un viaje de Comodoro hasta España, para luego retornar, uniendo así la costa patagónica con el viejo mundo. Este fue uno de las múltiples y numerosas formas de homenajear el inicio del "descubrimiento" y ocupación de América. Pero las conmemoraciones tenían también otro propósito: el pensar la herencia hispana como fundacional en la construcción de la "argentinidad" y, en este caso, en la historia y la población de Chubut.

A partir de principios del siglo XX, la elite intelectual argentina se abocó al proyecto de pensar la nacionalidad, construyendo sus elementos simbólicos, inventando y resignificando tradiciones y escribiendo una historia oficial, tarea iniciada centralmente por Bartolomé Mitre a partir de la segunda mitad del siglo XIX. El fin de este siglo había dejado al gaucho como uno de los principales elementos de la "tradición" argentina, planteando una hegemonía de esta figura mítica y ya perdida (GELMAN 1995), perteneciente a la pampa húmeda y especialmente al litoral, como representante identitario de un país mucho más extenso y diverso de lo que Buenos Aires era capaz de interpretar. Desde los retratos realizados por José Hernández, que luego fueron suavizados por el propio autor y por otros como Leopoldo Lugones o Ricardo Güiraldes, el gaucho comenzó a ser repensado un elemento central en la consturccion del "ser nacional" (INTERSIMONE 2007).

Los orígenes de la "argentinidad" fueron repensados, volviendo a la raíz colonial y rescatando la herencia hispánica. En ello influenció el $400^{\circ}$ aniversario del "descubrimiento" de América, que en España fue ampliamente festejada, al punto de realizar réplicas de las naves de Colón. En Argentina se realizaron además numerosos actos y monumentos en numerosas localidades. En Chubut, se erigió una pirámide en el pueblo de Gaiman, en el corazón de la colonia Galesa. Su constructor fue el italiano Francesco Pietrobelli, quien en 1901 fundaría Comodoro Rivadavia. Pero las buenas relaciones con España habían sido establecidas especialmente a partir de la década de 1860 , cuando la Corona española reconoció la independencia de Argentina. Por pedido de Vicente Fidel López, y ratificado en 1900 por el propio Julio Argentino Roca, el himno nacional fue recortado, dejando de lado su marcada hostilidad hacia España (CATTARUZZA 2007, p. 66).

El cambio de siglo trajo también para Latinoamérica una revalorización de la raíz hispana, especialmente en contraposición a la pretensión hegemónica 
estadounidense, simbolizada con la guerra de Cuba (1898). En este contexto, se estableció en Buenos Aires la Asociación Patriótica Española, que estuvo a cargo de presionar al gobierno para posicionar al 12 de octubre como una fiesta nacional. En 1917, bajo el gobierno de Yrigoyen, se define la fecha como "Día de la Raza", planteado explícitamente como un homenaje a España (CATTARUZZA 2007 , p. 83). El concepto de raza resultaba de interés para los intelectuales nacionalistas, como José Ingenieros, dedicados a definir una "raza argentina". El componente hispano será esencial a la hora de definir esta raza.

En relación a los sentidos político culturales atribuidos a la fecha, Alejandro Cattaruzza afirma que,

[...] a partir de la segunda mitad de los años veinte, ellos [los sentidos] volvían a cambiar, y desde algunos grupos del catolicismo español más tradicionalista se planteó la conveniencia de celebrar ya no el Día de la Raza, sino el día de la "Hispanidad". Con tal termino se aludía, de acuerdo con uno de sus promotores, al "conjunto de todos los pueblos de cultura y origen hispánico diseminados por Europa, África y Oceanía" y al "conjunto de cualidades que distinguen del resto de las naciones del mundo a los pueblos de cultura y estirpe hispana (CATTARUZZA 2007, p. 83-84).

En España, la fecha será definida por el franquismo como "día de la hispanidad" en la década de 1950.

En lo referente al caso chubutense, la presencia española en el territorio que posteriormente seria denominado Chubut había sido muy esporádica, en cuanto se encontraba, una vez establecida la Colonia, muy lejos de la frontera. Sin embargo, existieron momentos de contacto entre los españoles y el territorio.

El primero fue el desembarco de Simón de Alcazaba y Sotomayor, adelantado español que tenía por objetivo tomar posesión del territorio sudamericano por debajo del paralelo $35^{\circ}$ sur, en nombre de la corona española. Alcazaba desembarcó en 1535 en las cercanías del actual pueblo de Camarones. Tras una expedición hacia el interior del territorio, una parte de la tripulación se amotinó, asesinando a Alcazaba (DUMRAUF 1996, p. 65). La expedición fundó un asentamiento destinado a funcionar como base durante la expedición. Algunos historiadores consideran esto como la primera fundación de un poblado en el territorio argentino, ya que Buenos Aires fue fundada al año siguiente.

Posteriormente, en 1779 , se estableció un fuerte en la bahía San José, con el propósito de comenzar a controlar el tráfico marítimo rumbo al estrecho de Magallanes, así como de asegurar que ninguna potencia extranjera se estableciera en el territorio. Tres años antes se había creado el Virreinato del Rio de la Plata, comenzando sólo en este período un interés real de parte de la colonia española en proteger sus territorios coloniales más australes. Eventualmente, el fuerte fue atacado por indígenas y abandonado (DUMRAUF 1996, p. 108). Tras este establecimiento, la presencia europea (y estatal, pensando después de 1810) en la Patagonia y en Chubut fue esporádica, siendo la colonización galesa a partir de 1865 el próximo proyecto de establecimiento de hombres blancos en el territorio.

A partir de la provincialización del territorio chubutense, entre 1955 y 1958, surgió la necesidad de establecer una historia provincial, y un marco identitario 
que defina a su población. La colonia galesa representaba uno de los elementos más fuertes en este construcción, pero no era el "primer intento colonizador". En este marco, fueron rescatados la expedición de Alcazaba y el establecimiento del Fuerte San José.

A pesar de que la huellas de estos asentamientos son escasas o inexistentes, han representado elementos de interés a la hora de pensar la historia de Chubut, en particular para la comunidad española, que se ha esmerado en poner estos sitios y estas experiencias en valor, promoviendo el emplazamiento de monumentos para conmemorarlos. En el caso de la expedición de Alcazaba, se edificó una torre con una cruz, que simbolizaban de cierto modo la "Hispanidad". En diciembre de 1970 el sitio fue declarado "Lugar Histórico Nacional" por el Ministerio de Cultura y Educación de la Nación.

El ejemplo del fuerte San José representa el más interesante, en cuanto se construyó lo que se consideraba una réplica de la capilla original del fuerte. Según la investigación de Bianchi Villelli, Buscaglia y Sancci (2013), existió una confusión en lainterpretación de ciertos planos coloniales españoles que representaban un fuerte San José, pero que resultaron pertenecer a un emplazamiento defensivo de Montevideo, entonces en la Banda oriental del Uruguay.

De todas formas, el 9 de marzo, fecha de fundación de Nueva Leon, ${ }^{2}$ a pesar de ser una fecha reconocida en las efemérides provinciales, es un día laboral, a diferencia del 28 de julio, (aniversario del desembarco de los colonos galeses), y el 30 de abril, (aniversario del plebiscito del Río Corintos, cuando un grupo de habitantes de la cordillera, en su mayoría galeses, votaron por permanecer argentinos, en el marco del establecimiento de los límites con Chile, en 1902).

La principal objeción ante esta "infravaloración" de la experiencia exploradora española proviene de los círculos culturales hispánicos. En los últimos años, el Instituto argentino de cultura hispánica de Chubut "provincia de Nueva León, establecido en Rawson, capital de Chubut, ha abogado por una revalorización del evento. En 2009 publicó su boletín n. 2, referido enteramente a la "fundación de la provincia de Nueva León". La primera parte comprende un recuento histórico de la expedición de Alcazaba, desde los antecedentes y motivos hasta su desenlace. La segunda parte comprende una nota enviada al gobernador Mario Das Neves, en la que plantean que la conmemoración del 9 de marzo no debería representar únicamente a las comunidades españolas, sino a toda la población chubutense, citando antecedentes nacionales y provinciales de puesta en valor del evento y el lugar (Camarones), impartiendo así una "justicia histórica". Además, considera el evento de una relevancia similar al desembarco gales en 1865 . Sus propuestas, además de considerar tal fecha como día no laboral, consisten en pedir el cambio del nombre del Rio Chico a "Guadalquivir Chico" (como

\footnotetext{
2 En 1534, el Rey Carlos I de España firmo una capitulación concediendo la Gobernación de Nueva León al adelantado Simón de Alcazaba y Sotomayor. Este territorio comprendía una longitud de 200 leguas que se extendían desde la pampa húmeda argentina (y la zona de la actual Santiago de Chile) hasta la zona norte de la Patagonia. La historiografía dedicada a la expedición de Alcazaba menciona con múltiples nombres el asentamiento que el explorador funda en su llegada al territorio patagónico. Uno de los nombres es Puerto Leones, otro, Nueva León.
} 
lo había denominado la expedición) y establecer el hermanamiento de las ciudades de Camarones con León, en España.

Actualmente, la conmemoración no ha logrado consolidarse como una fecha relevante en el calendario festivo-litúrgico provincial. Los eventos conmemorativos se realizan principalmente en Rawson y en Camarones. Sin embargo, los actores centrales del evento continúan siendo las comunidades españolas, así como figuras representantes del gobierno español, en este caso, los vicecónsules honorarios de España (El Chubut, 12 de marzo 2014). Las autoridades presentes eran las locales y delegados del gobierno provincial. Notablemente, el gobernador provincial no se hace presente en los actos de los últimos años.

\section{La "experiencia española" en textos escolares provinciales.}

En 1978, las leyes 21.809 y 21.810 del Poder Ejecutivo Nacional transfirieron la educación primaria y secundaria al ámbito provincial (GONZALEZ; BETANCUR 2010, p. 113), y con ello la definición de los nuevos contenidos curriculares por parte del Consejo Provincial de Educación. Desde esta entidad, se propuso la creación de un libro de texto escolar, que tendría por objetivo cubrir el aprendizaje sobre los múltiples aspectos de la provincia. En ese mismo año el Consejo Provincial de Educación compiló una carpeta didáctica denominada Chubut mi Provincia, con información para elaborar el posible libro de texto escolar.

En sus primeras hojas podemos encontrar el objetivo de este nuevo programa: estudiar a la provincia en tres etapas, desde cuarto grado hasta

128 séptimo, con el objetivo de afianzar progresivamente los conocimientos de la provincia. Si bien es en cuarto año donde se cubriría la mayoría de los aspectos del conocimiento respecto a la provincia, entre quinto y séptimo se afianzarían mediante "un apropiado empleo del calendario escolar", culminando en séptimo grado, donde "se completa la visión del Chubut en el marco de la historia nacional, desde su poblamiento estable hasta el momento actual" (CARPETA Chubut mi provincia, 1978). Sus contenidos comprenden diversas áreas de estudio: geografía, clima, relieve, flora, fauna, población, e historia.

La información histórica provista por el documento es uno de los aspectos más ricos a analizar. Desde el comienzo, plantea una visión histórica de la provincia separada en dos grandes bloques, que son explicitados por dos diagramas que jerarquizan eventos y procesos. Ambos varían entre sí pero poseen el mismo sentido.

El primero de estos bloques refiere al contacto que tuvieron los españoles con el territorio chubutense, cubriendo esencialmente el periodo colonial. Este comprende dos puntos, siendo el primero denominado "primer intento colonizador", que cubre del descubrimiento de "Patagonia" por parte de Magallanes y la descripción de la región consolidada de la mano de Pigafetta, hasta la expedición de Simón de Alcazaba y Sotomayor, que representó la primera exploración del actual territorio chubutense por parte de europeos. El segundo punto comprende la historia del fuerte San José, pensado como el primer intento de establecer un asentamiento estable en el actual territorio chubutense, y la conflictiva relación con los indígenas. 
Fig. 1 - Primer cuadro de articulación de la historia de Chubut

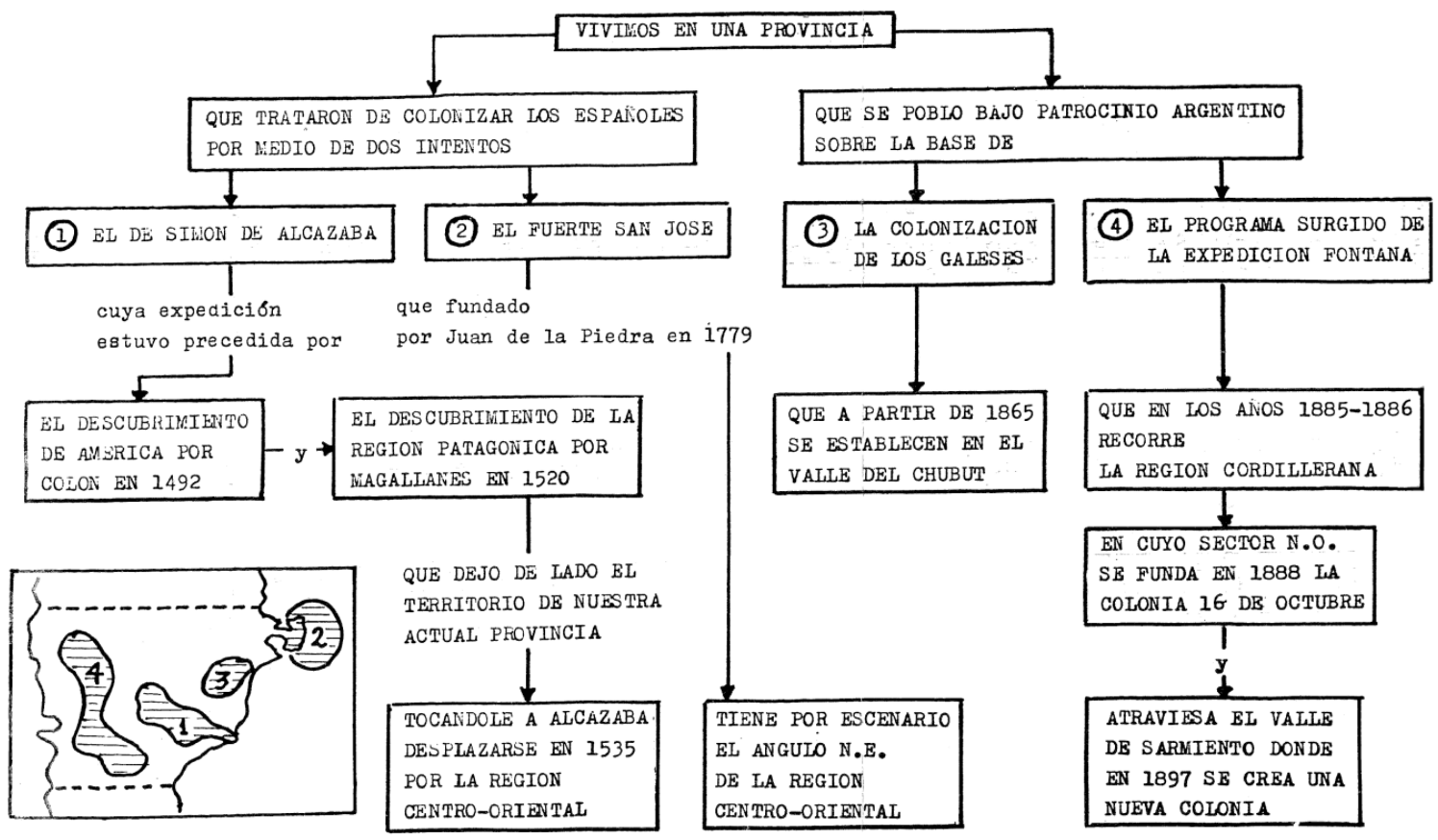

Fuente: Carpeta "Chubut mi provincia, Dirección Provincial de Educación, Chubut, 1978.

Estos dos diagramas poseen, sin embargo, diferencias que merece la pena mencionar. El primero responde a un cuadro en el cual se construye efectivamente - e intencionalmente - una jerarquización de los procesos referidos, ya que la explicación que acompaña el cuadro informa de la necesidad de hacer esto, creando, según dicha explicación, "núcleos determinantes". De esta forma, el cuadro se origina a través de la premisas "vivimos en una provincia", de la cual se desprenden las dos ramas principales "que trataron de colonizar los españoles por medio de dos intentos" (Alcazaba y fuerte San José) y "que se pobló bajo patrocinio argentino sobre la base de" (la colonización de los galeses y el programa surgido de la expedición Fontana). De estos cuatro puntos surgen otros puntos secundarios que pretenden cubrir la posterior expansión al resto de la provincia.

El segundo diagrama, como indicamos previamente, cubre las mismas temáticas pero explicitando los dos grandes bloques desde una óptica diferente, señalando un "Periodo colonial" y un "Periodo independiente", colocando además a los cuatro bloques secundarios en la misma jerarquía, enumerados cronológicamente, y con un "espíritu" más clasificador y menos determinista, ya que el primer cuadro, al conformarse con cuadros de texto consecutivos y orientados con flechas, implican una causalidad y una linealidad que el segundo no intenta evidenciar. Por demás, el segundo intenta ser más detallado en los subtemas a ver, a partir de subtítulos y contenidos.

Esta clasificación de la historia chubutense en cuatro grandes periodos concuerda además con la historizacion planteada por Virgilio Zampini en su libro Chubut: breve historia de una provincia argentina (ZAMPINI 1975). El autor siempre estuvo vinculado al ámbito cultural provincial por lo que es posible que su obra haya servido para compilar la carpeta. 
La carpeta incluye además material referido a la exploración española en Chubut, especialmente a la expedición de Alcazaba, en la que incluso aparece un borrador de una historieta sobre la expedición. En la década de 1980 esta historieta será concretada (con guion de Virgilio González e ilustraciones de Horacio Marras) y publicada. Hasta la década de 1990 fue publicada en el suplemento "Crónicas escolares" del diario Crónica de Comodoro Rivadavia. En la década de 2000 el fondo editorial provincial reeditó la historieta.

\section{El libro de texto Chubut mi provincia}

Este fue el primer libro de texto producido en el marco de las adecuaciones a la nueva ley de educación de 1978, y es el más conocido de los libros escolares de Chubut. Si bien data de la década de 1980, sigue siendo utilizado, en diversos niveles y de distintas formas, hasta la actualidad. El libro Chubut mi provincia ha tenido un uso y una distribución muy amplia, en especial debido a su fácil reproducción (está impreso en hoja oficio, por lo que puede ser fácilmente fotocopiado), lo que ha permitido la existencia de numerosas copias. Su autor es Marcelino Castro García, docente rionegrino con experiencia en la producción de libros escolares sobre las provincias patagónicas. El texto es acompañado por Mutisia, un libro adicional de lecturas también escrito por Castro García, al cual nos referiremos posteriormente.

Los aspectos históricos de la provincia son cubiertas en la cuarta sección del libro, "Antecedentes históricos, población", que comprende doce páginas.

130 El primer tópico abordado corresponde al de los pueblos originarios de Chubut, ocupando cuatro páginas para describir a los grupos tehuelches y mapuches. Posteriormente, bajo el subtítulo "exploradores blancos" el texto cubre el rol de los españoles en el descubrimiento, la exploración y la ocupación del territorio chubutense, comenzando con el viaje de Magallanes y el de Jofre de Loayza, que fue el primero en registrar algunos accidentes costeros de Chubut.

Posteriormente, y con mayor extensión, trabaja la expedición de Simón de Alcazaba y Sotomayor. Este es presentado efectivamente como un agente colonial, enviado por la corona española para tomar posesión del territorio. Prosigue mencionando la fundación de la población de Puerto Leones y la expedición hacia el interior de la provincia, y amotinamiento de parte de su tripulación, que termina con la muerte de Alcazaba. Luego, desarrolla brevemente la historia de la población en San José, explicando que se mantuvo por 30 años hasta ser arrasado por un malón en 1810. El texto finaliza afirmando que "así quedo nuevamente despoblada de blancos nuestra tierra, cuando ya la patria tenía su gobierno propio: la Primera Junta" (CASTRO GARCIA S/F, p. 25). Estos temas conforman la historia del territorio de Chubut en el periodo colonial.

Los textos son acompañados con ilustraciones. Las referidas a la exploración y la expedición de Alcazaba son, por un lado un grupo de naves acercándose a la costa, donde se pueden ver lobos marinos, y por el otro, a un hombre blanco (probablemente Alcazaba) en tierra firme con espada en mano y con dos barcos a su espalda. La referida al fuerte San José, sin embargo, representa una imagen violenta del malón que avanza hacia el fuerte para capturarlo. Resulta 
interesante ver que el fuerte no es retratado de acuerdo a como en ese momento se lo pensaba, con muros elevados de piedra, y edificaciones tales como la puerta de entrada o la capilla, sino que es presentado con una empalizada y una torre de madera, muy similar a como son representados los fortines de la frontera de Buenos Aires en el siglo XIX.

\section{Chupat Chubut}

La década de 1990 vio el surgimiento de un nuevo libro de texto destinado a cubrir el curriculum referido a la provincia de Chubut. En este caso, dos docentes de la provincia se dedicarían a confeccionarlo: Manuela Marcote Nemiña y Adelina del Rosario Magallanes de Orellana. El nuevo libro fue editado en 1991 por la editorial provincial Alfa, y poseía un diseño que difería notablemente con el del Chubut mi provincia, destinado a brindar información más sistemáticamente, tanto a través de texto como por medio de cuadros y fotografías.

Esta sistematización también se ve a la hora de cubrir la presencia española en el territorio chubutense, iniciando este periodo con el arribo de Colón a América. El viaje de Colón ocupa una página entera, incluyendo un mapa del trayecto. Tras esto, se narra el viaje de Magallanes y el encuentro de los europeos con Patagonia. En este contexto, las autoras aprovechan para definir los significados de "América", "Patagonia" y "Chubut". Resulta interesante que la Argentina no sea planteada como una entidad en este momento, ni siquiera para definir el territorio pasado desde una interpretación del presente, algo tan común en libros textos o libros de historias nacionales, donde siempre se plantea pensar al Estado nación como algo siempre presente.

Posteriormente, las autoras plantean cómo la corona española organizó el territorio sudamericano (incluyendo un mapa), desarrollando en este contexto la expedición de Alcazaba. El hombre es definido como "instruido, educado, perseverante y de nobles ideales" (MARCOTE NEMIÑA; ORELLANA DE MAGALLANES 1991, p. 52). La expedición es descripta desde su salida de España hasta su trágico desenlace en la costa chubutense. Presenta un dato erróneo, que contradice al texto anterior, en cuanto plantea que el asentamiento fundado se denominó "Nueva León". El texto presenta la expedición como esencialmente un fracaso, pero con el "gran valor de haber sido el primer reconocimiento del territorio chubutense y la primera fundación de la provincia del Chubut" (MARCOTE NEMIÑA; ORELLANA DE MAGALLANES 1991, p. 52-53). El texto es acompañado por un mapa del territorio de Chubut (con los límites provinciales delimitados) delineando el itinerario de los exploradores

Tras esto, las autoras trabajan la expedición de Juan de la Piedra y la fundación del fuerte San José. Presentan mucho detalle a la hora de hablar de la expedición, enfatizando las fechas en que partió y llegó, e incluso mencionando los buques participantes. El argumento que esgrime para justificar la expedición es el resguardo y protección de los territorios australes de la colonia, específicamente ante las aspiraciones inglesas. La empresa se vincula estrechamente con el descubrimiento del rio Negro y el establecimiento de un fuerte en su orilla, Carmen. En 1783, la corona ordena abandonar los fuertes al 
sur de Carmen, pero San José se mantiene con una guarnición mínima. El final del fuerte, ya en período de revolución (agosto de 1810) representa el fin del "primer intento de poblamiento de Chubut".

El libro Chupat Chubut es innovador en cuanto presenta la experiencia colonizadora española de Chubut en el marco general de la exploración y colonización de América, y no como un hecho aislado de la historia del resto del continente, o incluso del país.

La década de 1990 implicó para el sistema educativo nacional un periodo de reestructuración. En 1993 se sancionó la Ley Federal de Educación, que reformaba una ley vigente desde fines del siglo XIX (DOBAÑO FERNANDEZ; RODRIGUEZ 2009, p. 475). Estas reformas implicaron también cambios y una actualización de los contenidos en el área de las ciencias sociales (que comprendía Historia, Geografía, Educación Cívica y datos demográficos), así como un establecimiento de Contenidos Básicos Comunes a nivel nacional, y una reestructuración del ciclo educativo, denominado Educación General básica, con nueve años de duración. En Chubut, el sistema de Educación Nacional, que remplazó a la ley de 1993, reestructuró el esquema curricular, volviendo al esquema previo de escuela "primaria" y "secundaria". La actualización de los contenidos curriculares en las ciencias sociales a nivel nacional (que influenció los contenidos a nivel provincial) se enfocó principalmente en la integración regional latinoamericana, la causa Malvinas, los procesos de quiebre del orden institucional, democracia y estado de derecho, derechos de los pueblos originarios, e igualdad y respeto de géneros (DOBAÑO FERNANDEZ; RODRIGUEZ 2009, p. 478).

Paralelamente, los avances tecnológicos en diseño e impresión permitían una mayor facilidad en la producción de libros escolares, y aumentando la posibilidad de incluir imágenes a color, mapas o cuadros de texto.

Los dos textos a trabajar a continuación fueron producidos a fines de la década de 1990 y a fines de la década de 2000, aprovechando estos avances en diseño e impresión, logrando estructurarse y graficarse como los modernos libros escolares de uso a nivel nacional.

\section{Sentir Chubut}

El libro de texto Sentir Chubut fue editado en 1998, diseñado en Neuquén, e impreso en La Pampa por Ediciones Alfa, como parte de una serie de textos escolares sobre provincias argentinas. El equipo de realización es conformado, similarmente al Chupat Chubut, por dos docentes, una maestra normal nacional y una maestra normal superior y bachiller. Uno de los primeros elementos que lo diferencian de los libros anteriores es la referencia a los créditos de las fotografías y los textos utilizados, pertenecientes a diversas instituciones provinciales así como a particulares. Además, posee mayores dimensiones físicas que el Chupat Chubut.

La sección histórica es considerablemente más larga, tomando en cuenta otros temas no vistos en los documentos previamente analizados. La primera diferencia que se establece con los libros previos, pensando en los contenidos, es que el espacio que cubre ya no se circunscribe únicamente a la provincia del Chubut, sino que establece una óptica de estudio a nivel regional y trabaja la 
historia de la Patagonia. Al igual que en el Chubut mi provincia y en el Chupat Chubut, la sección histórica comienza con los pueblos originarios, bajo el título "civilizaciones patagónicas". Pero a diferencia de los libros de texto previos, este abarca la totalidad de la Patagonia y la zona sur de la región pampeana, para explicar sus áreas de movilidad. Resulta interesante ver cómo se explican los procesos de contacto entre grupos indígenas y los europeos, así como entre los propios grupos indígenas. De todas formas, se repiten ciertos estereotipos establecidos ya desde el Chupat Chubut, ${ }^{3}$ evidenciado una clara influencia literaria y narrativa sobre este libro.

En este texto, la presencia española en Chubut se enmarca, de forma similar al libro Chupat Chubut, al proceso de exploración y ocupación de América. A pesar de tener el enfoque en el territorio patagónico, no únicamente el chubutense, resalta la importancia de la expedición de Alcazaba en cuanto funda la primera ciudad en suelo argentino, algo que, según los autores es un hecho "[...] casi no reconocido por la historia argentina" (AGHEMO; TORRES 1996, p. 54).

Posteriormente, se cubre la historia de las diversas exploraciones de la Patagonia, especialmente en Neuquén, así como las relaciones con los indígenas en la frontera de la colonia. En ese sentido, la fundación de Carmen de Patagones es representada como un elemento central en la consolidación de estas relaciones, mientras que se menciona el establecimiento del asentamiento en el golfo San José, así como su duración por más de 30 años y su eventual fin, debido a la atracción que el ganado llevado allí generó a los grupos indígenas que habitaban el área.

Es de destacar que Chubut no es mencionado en ningún momento como una definición territorial ni identitaria. No parece adquirir la relevancia que se le otorgaba en los textos previos, lo que evidencia que no se intentó estructurar una historia de la provincial a partir de la jerarquización de hechos y eventos. Por el contrario, los eventos previamente estructurados como determinantes en la formación de la provincia y su sociedad son sólo unos entre tantos, muchos de los cuales se desarrollan fuera de la órbita chubutense. Claramente se está pensando en una óptica histórica a nivel regional y patagónico.

\section{Chubut pura naturaleza}

Chubut Pura Naturaleza es el último libro de texto editado por el Ministerio de Educación de la provincia. Fue concebido en el marco de la Nueva Ley de Educación Nacional, que remplazó al anterior sistema del EGB, e introdujo temáticas nuevas en el curriculum de ciencias sociales que representan elementos que aparecen en la actual agenda pública, como derechos humanos, derechos de los pueblos originarios o igualdad de género.

\footnotetext{
${ }_{3}^{3}$ Especialmente en los conceptos propuestos por el arqueólogo Rodolfo Casamiquela respecto a tehuelches y mapuches, en lo referido al concepto de araucanización, unido al de tehuelchización. este libro condensa estas ideas a través de un cuadro comparativo entre ambos grupos étnicos, que los clasifica mediante variables como: aspecto físico, aspecto moral, vestimenta, armas, alimentación, organización social o costumbres. Las conclusiones que el cuadro presentaría indicarían que, mientras el indígena tehuelche es alto, fornido, inteligente y pacífico, el mapuche es "achaparrado" y belicoso.
} 
El libro fue publicado en 2006, y parece haber sido efectivamente construido por un equipo de realización, ya que en los anteriores la autoría recaía en uno o dos individuos. Además, se resalta la participación de un docente universitario de Historia.

Ya desde el título de la sección "histórica" encontramos diferencias con las publicaciones anteriores, el cual es "El tiempo y el espacio. Construir la memoria y la identidad colectiva". En cierto modo plantea que todo aquello que abarca la unidad, conforma la "identidad chubutense". Este es un importante giro discursivo respecto a los textos anteriores, especialmente al Sentir Chubut, desde el cual se pensaba una óptica regional en la que lo provincial se diluía entre procesos más abarcativos.

Por otro lado, el inicio de esta sección resulta interesante en cuanto, antes de dedicarse a presentar los datos y los hechos históricos al alumno, provee de herramientas para su comprensión: opta por explicar, sintética y simplemente, qué es el tiempo y la Historia, la existencia de causas y consecuencias, utilización de fuentes y la multiplicidad de estas, así como la variedad de miradas con las que se pueden abordar (SEIJO DE FRAGOZA 2006, p. 92-93). Al igual que los textos ya trabajados, el tópico de los pueblos originarios da comienzo a la sección histórica, pero con una interpretación actualizada de la historia de estos grupos. Por un lado, introduce el concepto de "pueblo originario" el cual es el más aceptado en la actualidad, aunque ocasionalmente se utiliza "indígenas". Por el otro, no se los piensa como extintos, sino como un grupo y una cultura todavía vigente, con reclamos legítimos y con el derecho a ser reconocidos. Esta es una reproducción de las políticas del gobierno del período, orientado hacia un reconocimiento de los grupos representantes de pueblos originarios en la provincia.

Este texto continúa con la tradición narrativa iniciada en el Chupat Chubut, de inscribir la expedición de Alcazaba en el contexto de exploración por parte de los conquistadores españoles. Se describen brevemente las expediciones de Colón y el viaje de Magallanes, donde la Patagonia (y sus habitantes) son narrados por primera vez por los europeos. En este contexto, los autores mencionan este periodo como "época colonial", en cuanto "América fue gobernada por autoridades de España" (SEIJO DE FRAGOZA 2006, p. 116).

La expedición de Alcazaba comprende un apartado que cubre tres páginas, mucho más que en los libros anteriores. A diferencia de los textos anteriores, la figura del adelantado no es descrita, pero si (aunque muy simplificadamente) las causas de su expedición. La llegada al actual territorio chubutense y la expedición hacia su interior es cubierta bajo el título "la primera fundación". Sin embargo, no se menciona la fundación de un poblado, sino de la provincia de Nueva León. De todas formas, el texto pone en valor esta acción en cuanto finaliza explicando que "La misión colonizadora había fracasado. Sin embargo, la expedición fue muy importante, por ser la primera fundación en el territorio del Chubut" (SEIJO DE FRAGOZA 2006, p. 117). Es interesante que no se la mencione como la primera fundación en suelo argentino, algo que definitivamente le daría un valor mucho mayor a la experiencia. 
Respecto al establecimiento del fuerte San José, el libro presenta una contextualización del establecimiento de asentamientos españoles en la zona a partir de los viajes exploratorios de europeos en Patagonia en el siglo XVIII, especialmente el de Thomas Falkner. Las descripciones positivas de los territorios patagónicos, y la posibilidad de ocupación por otras potencias europeas llevan a la corona española a ordenar el establecimiento de puestos en el territorio.

La historia del fuerte San José es básicamente descrita como trágica, e interesantemente no se la vincula a la exploración del rio Negro y el establecimiento del Carmen de Patagones, como lo hacen los otros libros de texto, aunque es mencionado tangencialmente. Juan de la Piedra es mencionado pero no se explicita nada de esta figura.

Explica el estado de abandono del fuerte al decir que España estaba en guerra con otros países europeos, por lo que era incapaz de mantener estos puestos lejanos. El texto afirma que "esto determinó que las costas patagónicas siguieran abandonadas durante mucho tiempo" (SEIJO DE FRAGOZA 2006, p. 120). Este problema fue heredado por el gobierno patrio a partir de 1810. La última parte del texto afirma que "como consecuencia, estas regiones volvieron a ser descuidadas".

En definitiva, la experiencia exploradora y colonizadora española es valorizada por representar los primeros intentos de asentamientos, pero es evidente, según el texto, que dichas experiencias no dejaron una impronta significativa o duradera en la población. Más adelante, se evidencia una centralidad de la colonización galesa en el proceso poblacional del territorio chubutense, en cuanto ocupan una porción significativa del texto, considerablemente mayor a las de la "experiencia española".

\section{Consideraciones finales}

A pesar de representar hitos relevantes en la historia de la ocupación europeaestatal en el actual territorio chubutense, la experiencia exploratoria y ocupacional española en los siglos XVI y XVIII-XIX no logra dejar el plano de lo anecdótico a la hora de pensar la historia de Chubut. En el caso de los libros de texto escolares, el reducido espacio otorgado a las temáticas históricas permite que eventos como la expedición de Alcazaba o la instalación de un fuerte en península Valdez ocupen tanto espacio como la organización de los pueblos originarios, la colonización galesa o los últimos 50 años de historia provincial. En la medida que estos libros aumentan de tamaño, pensando especialmente en Chubut Pura Naturaleza, se percibe un menor otorgamiento de espacio textual a estas experiencias respecto a otros procesos más significativos en la historia de Chubut.

Respecto a estos episodios de protagonismo español, a pesar que ambos aparecen en los libros de texto, en ninguno obtienen la preponderancia pretendida por las comunidades que valorizan la herencia hispánica en la provincia, pero se otorga un rol significativo, como la primera exploración del territorio chubutense, en el marco de la época de exploración en el siglo XVI, y como el primer intento de ocupación por parte del Estado (en este caso, el colonial español) en el actual territorio provincial. Esta importancia, sin embargo, varía entre los diversos textos. 
Mientras la carpeta compilada por el Consejo Provincial de Educación explicitaba estos dos eventos como pilares de la historia provincial (junto con los episodios relacionados con la colonización galesa y su expansión hacia el oeste), algo compartido por el libro de texto Chubut mi provincia y el Chupat Chubut, estos episodios son pormenorizados en Sentir Chubut, en cuanto plantea un enfoque másregional a nivel patagónico, donde otros eventos, como la fundación de Carmen de Patagones, y la expansión de la frontera ganadea de buenos aires adquieren mayor relevancia. Finalmente, el libro Chubut pura Naturaleza otorga mayor importancia (y desarrollo) a estos temas, explicitando la importancia de estos eventos en la historia del territorio chubutense.

A pesar de no contar con una bibliografía, es posible determinar que estos textos se nutrieron de producciones historiográficas sobre la historia de Chubut, particularmente la obra de Virgilio Zampini (1975) y, posteriormente, Clemente Dumrauf (1991). Sin embargo, se importante remarcar que estos textos provienen de diferentes contextos de producción. En los casos de Chubut mi provincia y Sentir Chubut, los autores no son chubutenses, y han producido textos escolares para varias provincias. En el caso de Chupat Chubut, el texto fue producido y editado en Comodoro Rivadavia.

Si bien la bibliografía con la que hemos pensado al libro de texto interpreta al mismo esencialmente como un producto surgido como resultado de un discurso específico sobre la historia nacional, es posible que en la esfera provincial la dinámica sea distinta, en cuanto la intervención de la agencia estatal, si bien

136 ha sido planificada (como demuestra la compilación de la carpeta Chubut mi Provincia), no es posible ver en los la mayoría de estos textos. Únicamente Chubut pura Naturaleza responde a un proceso de producción que parte del Estado provincial.

De todas formas, a la hora de pensar en la constitución de una narración histórica oficial de Chubut, la experiencia galesa continúa siendo el elemento central a la hora de escribir la historia provincial en estos textos.

\section{Referencias bibliográficas}

AA.VV. Carpeta Chubut mi provincia. Consejo Provincial de Educación, Chubut, 1978.

AGHEMO, Vilma Isidora; TORRES, Olga Nélida Elsa. Sentir Chubut: manual de apoyo para la Educación General Básica. Bahía Blanca: Alfa Centro Literario, 1998.

CASTRO GARCIA, Marcelino. Chubut mi provincia. Ciencias sociales, II Ciclo, Escuela Primaria, Rio Negro

Mutisia. Lecturas, Chubut, II Ciclo, Escuela Primaria. Rio Negro (sin fecha)

CATTARUZZA, Alejandro. Los usos del pasado. La historia y la política argentinas en discusión, 1910-1945. Buenos Aires: Sudamericana, 2007. 
CUCUZZA, Rubén Héctor. Yo argentino. La construcción de la Nación en los libros escolares (1873-1930). Buenos Aires: Miño \& Dávila, 2007.

DEVOTO, Fernando. Idea de Nación, inmigración y cuestión social en la historiografía académica y en los libros de texto de Argentina (19121974). Estudios Sociales, n. 3, p. 9-30, 1992.

DOBAÑO FERNANDEZ, Palmira; RODRIGUEZ, Martha. Los contenidos de los libros de texto escolares de historia y ciencias sociales 1983-2006. En: AA.VV. Seminario Internacional "Textos Escolares de Historia y Ciencias Sociales". Santiago de Chile: Ministerio de Educación, 2009, p. $475-486$.

DUMRAUF, Clemente I. Historia de Chubut. Buenos Aires: Editorial Plus Ultra, 1991.

El Chubut, Trelew, 12 de Marzo 2014. Disponible en: http://www.elchubut. com.ar/nota/83655/.

GELMAN, Jorge. El gaucho que supimos conseguir. Determinismo y conflicto en la historia argentina. Entrepasados, año V, n. 9, p. 27-37, 1995.

INTERSIMONE, Luis Alfredo. El discurso nacionalista de Don Segundo Sombra, Alpha, n. 24, Osorno, p.165-176, 2007.

JOHNSEN, Egil Børre. Libros de texto en el calidoscopio. Barcelona: PomaresCorredor, 1996.

MARCOTE NEMIÑA, Manuela; MAGALLANES DE ORELLANA, Adelina del Rosario.

Chupat Chubut. Comodoro Rivadavia: Alfa Centro Literario, 1991.

NEGRIN, Marta. Los manuales escolares como objeto de investigación. Educación, lenguaje y sociedad, v. VI, n. 6, p. 187-208, 2009.

ROMERO, Luis Alberto (coord.). La Argentina en la escuela. La idea de nación en los textos escolares. Buenos Aires: Siglo XXI, 2004.

SEIJO DE FRAGOZA, Marta (coord.). Chubut pura naturaleza, 4 año EGB 2. Ministerio de Educación de la Provincia de Chubut, 2006.

ZAMPINI, Virgilio. Chubut. Breve historia de una provincia argentina. El Regional: Gaiman, 1975. 